\title{
MEMORIA DE LA SECRETARÍA GENERAL DEL AÑO 2020
}

\author{
José Miguel García Sagredo
}

Académico de Número de la Real Academia Nacional de Medicina de España - Genética Humana

Académico Secretario General de la Real Academia Nacional de Medicina de España

Con la venia del Sr. Presidente voy a dar lectura a la Memoria de actividades de la RANME en el año 2020 tal y como lo establecen los Estatutos en el artículo 44/9: Redactar la memoria que cada año ha de leer en la sesión pública inaugural, presentando en ella un resumen de las tareas en que se ha ocupado la real academia durante el año anterior.

Excelentísimos Sr Presidente de la RANME, Excelentísimas y Excelentísimos señoras y señores académicos, premiados, señoras y señores, al iniciar 2020 estábamos preparados para un cambio de década muy feliz, cambio de década que deseamos que signifique algo nuevo, en el que hacemos con más ahínco nuevos propósitos $y$, repentinamente, nos hemos encontrado con un año 0 . ¿Qué significa año 0 ?, un cambio repentino y radical, hasta el punto de que podríamos decir que a partir de ahora empieza un nuevo siglo, una nueva era. Estoy casi seguro que, dentro de un año, cuando haga la memoria anual hablaré de las noticias de un nuevo siglo que empieza hoy mismo.

2020 se inició en la RANME el 14 de enero pasado con un acto en el que esta sala de sesiones estaba llena, sin asientos vacíos. En esta sesión inaugural, tras la lectura de la memoria por el entonces secretario general Prof. Luis Pablo Rodríguez Rodríguez, se impartió la

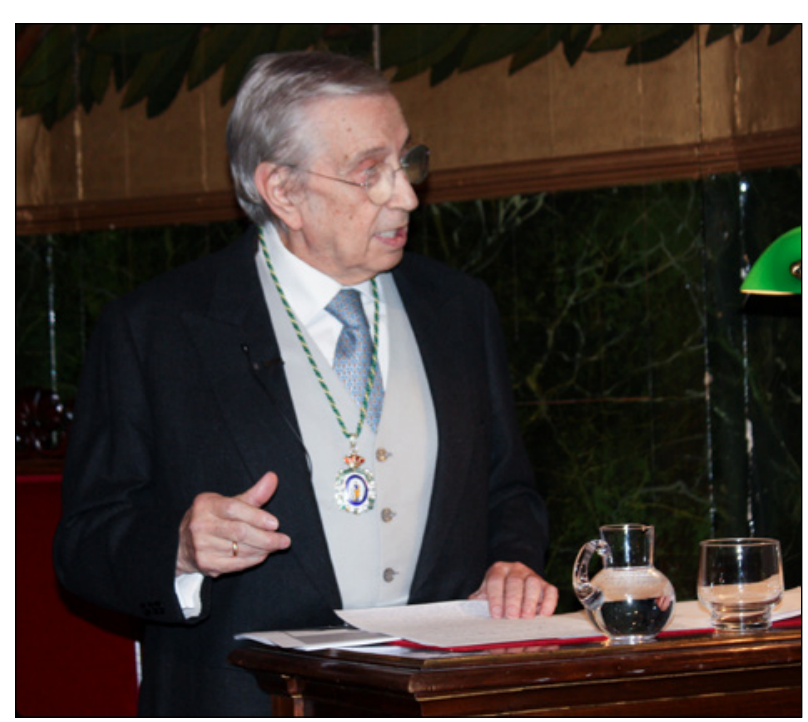

El entonces secretario general Prof. Luis Pablo Rodríguez Rodríguez lección de precepto por el Prof. Enrique Moreno sobre la evolución de los trasplantes de órganos abdominales y se entregó la placa de antigüedad académica al Prof. Rubia Vila, para proceder inmediatamente a la entrega de los premios de la RANME.

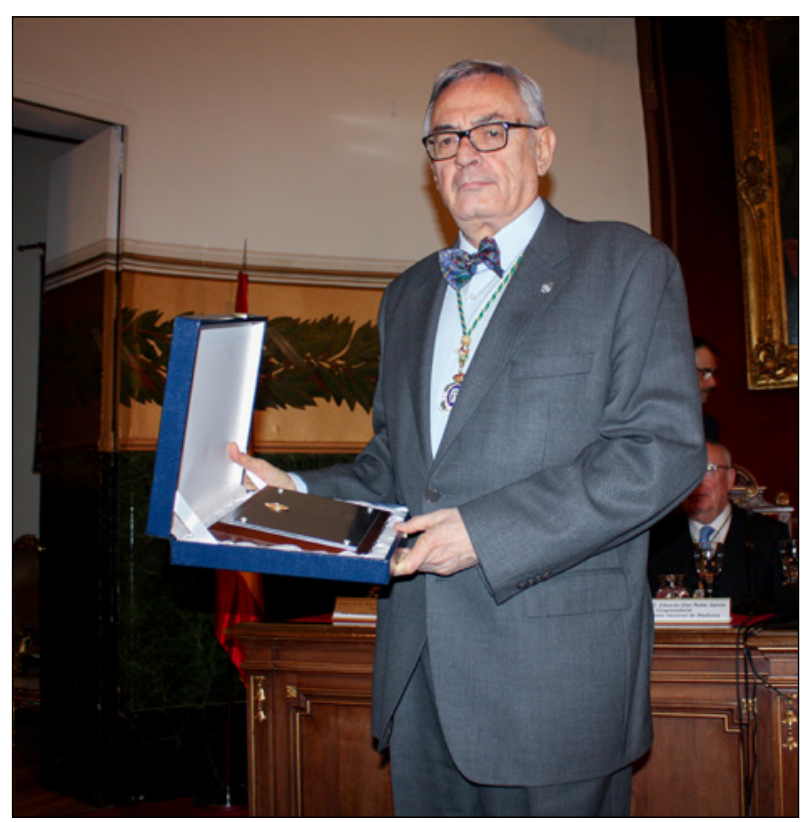

Entrega de la placa de antigüedad académica al Prof. Rubia Vila

La actividad de la RANME prosiguió con normalidad hasta el día 3 de marzo en el que tras la sesión ordinaria se anunció la suspensión de la actividad académica, 10 días antes de que el Gobierno de España decretara el estado de alarma. Pero como no podía ser de otra forma, la Junta Directiva decidió reanudar la actividad académica de forma telemática el 19 mayo, actividad que no se ha interrumpido hasta hoy.

El año 2020 ha servido para demostrar que la RANME es capaz de cumplir sus cometidos y seguir trabajando a pesar de las restricciones, que es capaz de aprender a utilizar con eficacia las tecnologías, incluso aumentando la participación de los académicos de forma que el servicio a la sociedad no se ha visto interrumpido. De ello dará fruto el relato que sigue de esta memoria. 
Evidentemente dos terceras partes de esta memoria pertenece a la Junta Directiva anterior que fue renovada en la Junta de Gobierno del 8 julio y finalizada con la elección del Vicepresidente el 1 de diciembre, quedando compuesta por:

Presidente: Eduardo Díaz-Rubio

Vicepresidente: Antonio Campos

Secretario General: quien les habla

Tesorero: Jose Luis Carreras

Secretario de Actas: Ana Villegas

Contador: Gonzalo Piédrola

Bibliotecario: Julian García Sanchez

Además de realizar las sesiones de la Academia de forma telemática, era necesario continuar la vida académica de forma eficiente, por lo que, propiciado por la nueva junta directiva, ha sido necesaria una adaptación del reglamento permitiendo las juntas de gobierno y las votaciones secretas tambien de forma telemática.

Pero antes de continuar, permítanme que haga un sentido homenaje a los académicos que nos abandonaron, José Maria Gil-Vernet Vila, que ostentaba el sillón 14 de Urología desde 2008 que fue pionero de los trasplantes de órganos en España.

Juan Jiménez Collado, cuyo sillón 49 de Biología del desarrollo y genética ocupaba desde 1993 y que fue Secretario General de 1999 a 2004.

Francisco Alonso Fernández, sillón 16 de Psiquiatría desde 1979. Autor de numerosos artículos y libros, entre otros sobre Goya, Santa Teresa o Don Quijote.

En este momento, quiero recordar que se celebraron las siguientes Sesiones necrológicas:

Sesión necrológica en memoria del Prof. Portera con el discurso de precepto a cargo del Prof. Francisco J. Rubia.

Sesión necrológica en memoria del Prof. Gil Vernet con el discurso de precepto a cargo del Prof. Arturo Fernández Cruz.

Sesión necrológica en memoria del Prof. Jimenez Collado con el discurso de precepto a cargo del Prof. Pedro Guillén García.

Como la vida académica sigue, a lo largo del 2020 pudieron elegirse los siguientes académicos:

Miguel Sánchez Garcia que ocupará el sillón número 10 dedicado por primera vez a la Medicina Intensiva. El Prof. Sánchez Garcia es Jefe del Servicio de Medicina Intensiva del Hospital Clínico San Carlos de Madrid desde 2007 y Profesor asociado al Departamento de Medicina de la Universidad Complutense de Madrid.

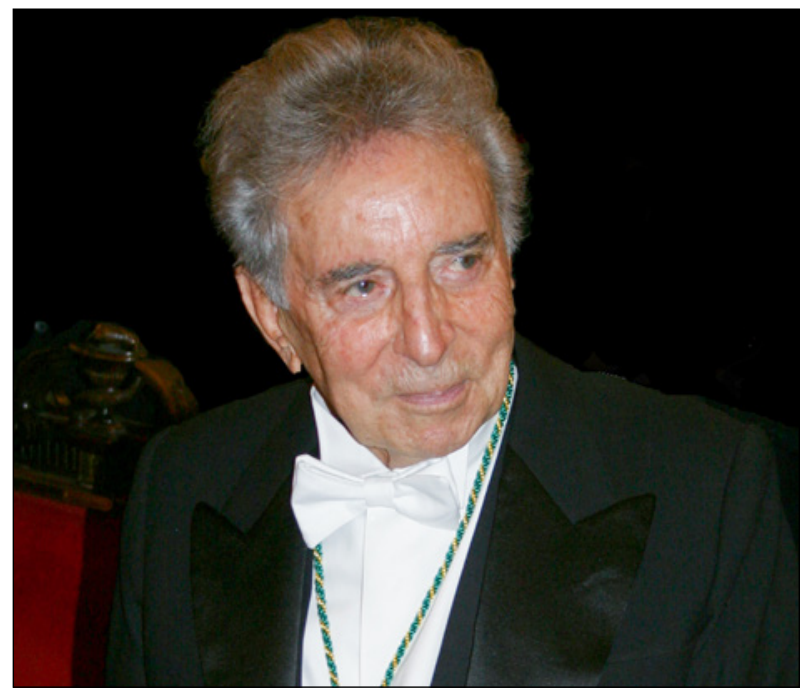

José María Gil-Vernet

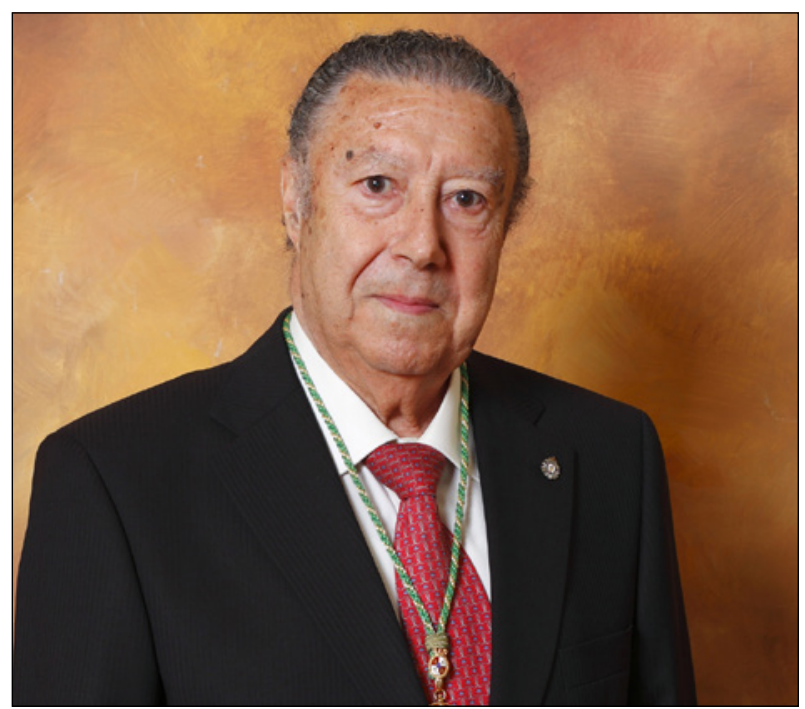

Juan Jiménez Collado

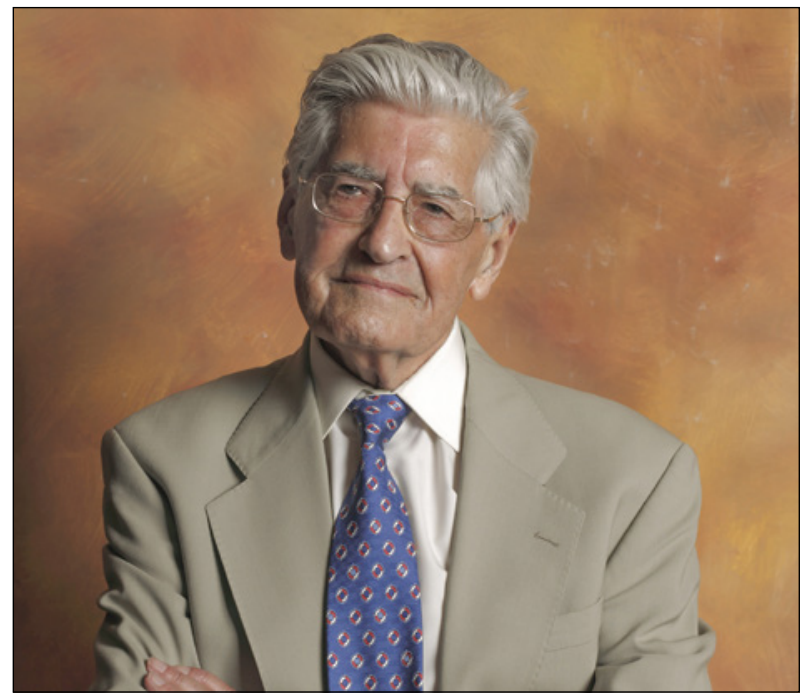

Francisco Alonso Fernández 
Jorge Alvar Ezquerra FOTO elegido como Académico de la Real Academia Nacional de Medicina de España para ocupar el Sillón número 26, Medicina Preventiva y Social. El Dr. Alvar Ezquerra era ya miembro de la RANME desde el año 1994 en el que recibió el título de Académico Correspondiente al ser reconocido con el Premio de la Academia dicho año.

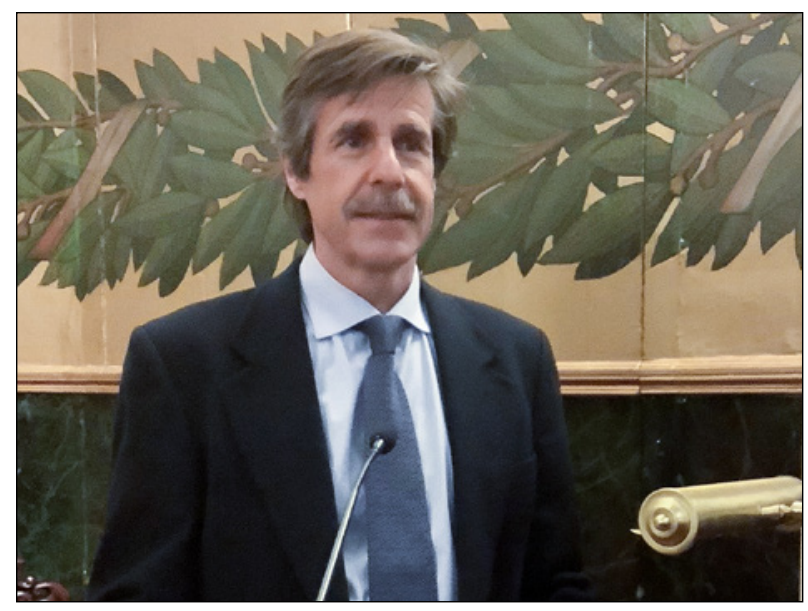

Miguel Sánchez García
Como es costumbre, todos los martes se celebran sesiones ordinarias en que los Académicos tanto de número como correspondientes disertan sobre algún tema de actualidad referente a su especialidad.

A lo largo del año se han realizado 22 Sesiones Científicas Ordinarias con 42 ponentes.

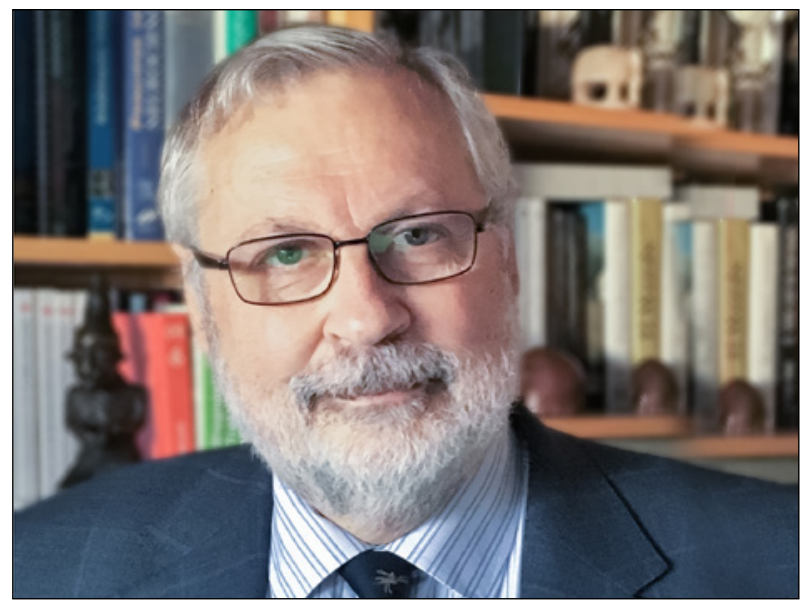

Jorge Alvar Ezquerra

\begin{tabular}{|c|c|}
\hline Imagen médica en pacientes infectados con COVID-19 & Prof. Luis Martí Bonmatí \\
\hline La respuesta de la medicina intensiva en Madrid al COVID-19 & Prof. Miguel Sánchez García \\
\hline SARS-CoV-2: problemas e incertidumbres & Prof. Ma del Carmen Maroto Vela \\
\hline $\begin{array}{l}\text { Crisis COVID-19: perspectiva epidemiológica y social de una pandemia sin prece- } \\
\text { dentes en nuestra vida }\end{array}$ & Prof. José María Martín Moreno \\
\hline Cómo defendernos frente a virus emergentes: vacunas y COVID-19 & Prof. Mariano Esteban Rodríguez \\
\hline El COVID-19 y su patología: qué sabemos & Prof. Santiago Ramón y Cajal Agüeras \\
\hline COVID-19 y el tema de las residencias: algunas reflexiones & Prof. José Manuel Ribera Casado \\
\hline $\begin{array}{l}\text { La calidad de la asistencia médica al final de la vida. ¿También en tiempos de } \\
\text { crisis sanitaria }\end{array}$ & Prof ${ }^{a}$. María Castellano Arroyo \\
\hline Papel de la respuesta inmunitaria en el COVID-19 & Prof. Emilio Gómez de la Concha \\
\hline Los genes de la susceptibilidad a COVID-19 & Prof. Antonio José López Farré \\
\hline Historia de las pandemias. De la peste a la COVID-19 & Prof. Javier Sanz Serrulla \\
\hline Reflexiones sobre la pandemia por COVID-19 en los países en vías de desarrollo & Prof. Jorge Alvar Ezquerra \\
\hline La Hipertensión Arterial Pulmonar en las Enfermedades por COVID-19 & Prof. José Ramón de Berrazueta \\
\hline $\begin{array}{l}\text { Cirugía traumatológica urgente en pacientes con COVID-19 positivo en plena } \\
\text { pandemia }\end{array}$ & Prof. Pedro Guillén García \\
\hline Manifestaciones neurológicas del Covid-19 & Dr. Juan Carlos García Moncó \\
\hline Covid-19 y neurodegeneración: presente y futuro & Dra. Mariana Hernández González-Monje \\
\hline La infección del Covid-19 en el embarazo. Normas asistenciales & Prof. José Antonio Clavero Núñez \\
\hline La Medicina Nuclear durante la pandemia Covid19 & Dr. Joan Castell Conesa \\
\hline El impacto en salud mental del Covid-19 & Profa Dña. Ma Inés López-Ibor Alcocer \\
\hline “QQué hemos aprendido de la coagulopatía trombótica en COVID-19? & Dr. Vicente Vicente García \\
\hline $\begin{array}{l}\text { Enfermedad renal crónica: el factor de riesgo para COVID-19 grave más preva- } \\
\text { lente y que más riesgo confiere }\end{array}$ & Prof. Alberto Ortiz Arduan \\
\hline Covid-19 y enfermedad hepática & Prof. José Luis Calleja Panero \\
\hline Covid-19 y enfermedad digestiva & Prof. Agustín Albillos Martínez \\
\hline Genética del huésped en Covid 19 & Prof. Ángel Carracedo Álvarez \\
\hline Genética del huésped en Covid 19 & Dr. Pablo Lapunzina Badia \\
\hline Ciencia y Medicina en tiempos de pandemia & Ilma. Sra. Dña. Raquel Yotti Alvarez \\
\hline
\end{tabular}

Tabla 1. Sesiones Científicas Ordinarias 
5 previas a la pandemia y el resto concernientes al tema COVID-19 o los efectos colaterales o secundarios provocados por la Covid-19.

En conjunto han participado 21 Académicos de Número, 16 Académicos Correspondientes y 7 ponentes de reconocido prestigio.

Quiero destacar los temas tratados sobre SarsCov2, Covid-19 y efectos colaterales.

Sobre el SarsCov2 se trató de la naturaleza del virus, la epidemiología y las posibles vacunas. Sobre la COVID-19 se disertó sobre imagen médica, anatomía patológica, tratamiento en UCI, inmunidad, genes de susceptibilidad, hipertensión pulmonar, embarazo, neurología, nefrología, hematología, impacto en las residencias y calidad de asistencia al final de la vida.

Sobre los efectos secundarios en la salud las ponencias han sido:
"Impacto de la vacunación frente a tos ferina en España" Coordinado por el Prof. Angel Gil de Miguel En colaboración con Sanofi Pasteur.

Día mundial de la visión, Coordinada por los Profesores Julián García Sánchez y Miguel AngelZato Gómez de Liaño En colaboración con la Fundacion de la Sociedad Española de Oftalmología.

"Estrategias de vacunación frente a la gripe", Coordinado por el Prof. Angel Gil de Miguel En colaboración con Sanofi Pasteur.

Foro “Teófilo Hernando" de Jóvenes Investigadores En colaboración con la Fundacion Teófilo Hernando $($ FTH) y la Fundación ASISA: "Heterogeneidad del cáncer de mama: identificación de Vulnerabilidades terapéuticas" por el Dr. Alberto Ocaña Fernández.

XVII Curso de Fundamentos moleculares de la medicina, Coordinado por el Prof. Enrique Blázquez

\begin{tabular}{ll}
\hline Cáncer infantil y COVID-19: experiencia inicial & Prof. Luis Madero López \\
\hline El manifiesto Healthy and Green recovery after COVID-19 & Dra. Da. María Neira \\
\hline Covid-19 y cáncer & Prof. Mariano Provencio Pulla \\
\hline $\begin{array}{l}\text { Influencia de la pandemia en el trasplante de órganos } \\
\text { La Medicina Nuclear durante la pandemia Covid19 }\end{array}$ & Prof. Enrique Moreno González \\
\hline El impacto en salud mental del Covid-19 & Dr. Joan Castell Conesa \\
\hline $\begin{array}{l}\text { Los hospitales en la covid19: retos y oportunidades para la } \\
\text { formación }\end{array}$ & trans- \\
\hline
\end{tabular}

Tabla 2. Sesiones sobre El SarsCov2, Covid-19 y efectos colaterales.

El año 2020 se cerró el 15 de diciembre con la Solemne Sesión de Clausura del Curso Académico de forma semipresencial con la conferencia "Ciencia y Medicina en tiempos de pandemia" pronunciada por la Ilma. Sra. Dña. Raquel Yotti Alvarez, Directora del Instituto de Salud Carlos III - ISCIII

Adicionalmente a las sesiones ordinarias de los martes, se celebraron Sesiones extraordinarias de la que quiero destacar.

"Fundamentos de alergia e inmunología clínica" Coordinada por el Prof. Tomás Chivato Pérez Con la colaboración de Leti Pharma.

"Enfermedades tropicales desatendidas y objetivos sostenibles del milenio: necesidades terapéuticas para su eliminación en 2030" Coordinada por el Prof. Gonzalo Piédrola Angulo Con la colaboración de GSK y DnDi - Drugs for Neglected Diseases initiative.

MEDICINA FÍSICA Y REHABILITACIÓN HOY Y ¿MAÑANA? PARA LOS PACIENTES COVID-19 Coordinado por el Prof. Luis Pablo Rodríguez Rodríguez, Con la colaboración de la Fundación ASISA. y con la colaboración de la Fundación ASISA con un amplio Panel de ponentes entre los que destacan: Prof. José Miguel Garcia Sagredo, María Salazar, María Blasco, Garcilaso Riesco, Manuel Serrano Marugán, Pedro Ramos, Miguel Angel Pozo, Sebastián Cerdán, $M^{a}$ Nieves Cabrera, Rosa Couto, María Pedrera, Aída Ortega y José Luis Carreras Delgado.

Por último, el 9 de diciembre se celebró la sesión extraordinaria sobre Virus del Nilo Occidental, con la coordinación de la Profa. María del Carmen Maroto Vela, en colaboración con la FRANM.

La VII Semana Santiago Ramón y Cajal coordinada por el Prof. Obeso con la colaboración de la Fundación Tatiana Perez de Guzman se celebró del 13 al 16 de octubre en la que se enmarcó la Sesión ordinaria del 13 de octubre la SESIÓN CIENTÍFICA “INICIO Y PROGRESIÓN DE LA NEURODEGENERACIÓN EN LA ENFERMEDAD DE PARKINSON" en la cual participarán el Excmo. Sr. D. José Obeso Inchausti, Académico de Número con la exposición "Patrón de Neurodegeneración Nigro-estriatal en la enfermedad de Parkinson inicial - Importancia etiopatogénica", y la Ilma. Sra. D. a Carmen Cavada Martínez, Académica Correspondiente de la RANME, que habló sobre la 
"Vulnerabilidad neuronal en el cerebro parkinsoniano: investigación en primates no humanos".

El 14 de octubre el FORO “TEÓFILO HERNANDO” DE JÓVENES INVESTIGADORES, iniciativa organizada en colaboración con el Instituto Teófilo Hernando y el apoyo de la Fundación ASISA. El investigador Dr. Juan Fortea Ormaechea disertó sobre "La enfermedad de Alzheimer preclínica esporádica, autosómico dominante y asociada al síndrome de Down.

El 16 de octubre el "I SIMPOSIO FERNANDO REINOSO SUÁREZ" el cual versó sobre "El Dolor Patológico". estubo dirigido por la Profa Carmen Cavada y organizado por la Cátedra Universidad Autónoma de Madrid-Fundación Tatiana Pérez de Guzmán el Bueno en la que participaron destacados expertos en la materia.

Una Sesión fuera de los muros de esta Academia que merece mencionar aquí fue la Apertura del curso de las Reales Academias 2020-2021. El pasado 7 de octubre, Su Majestad el Rey, Felipe VI, presidió en la Real Academia Española de la lengua la solemne apertura del curso de las Reales Academias del Instituto de España, en un acto en el que estuvo acompañado por el ministro de Ciencia e Innovación, Pedro Duque, y el director de la RAE, Santiago Muñoz Machado. Por motivos obvios la asistencia era muy limitada pero en la que estuvieron presentes el Presidente Prof. Eduardo Díaz-Rubio, el Secretario General, quien les habla, y el Prof. Jesus Fernández Tresguerres.
Otra sesión externa e itinerante anual es la que organizan las cuatro reales Academias Científicas: Medicina, Farmacia, Ciencias e Ingenieros denominada Tetraca. Por motivos obvios no se pudo celebrar en 2020 por lo que también se ha retrasado, este año le tocó a la RAI que ha elegido Covid-19 y que se celebrará los próximos 18 y 19 de enero.

La RANME pertenece a la FEAM (Federación de Academias de Medicina Europeas): Se publicó el informe "Challenges and potential in regenerative medicine" elaborado por las academias de medicina europeas FEAM y de ciencias EASAC y del que ha sido colaborador y ponente el Académico Prof. Antonio Campos.

ALANAM, la asociación de Academias Latinoamericanas a las que también pertenece la RANME, celebró el 24 de octubre de 2020 la XXV Reunión del Consejo Directivo de forma virtual. El tema de la reunión fue "Lecciones aprendidas en cada país sobre la pandemia COVID 19 y las recomendaciones a los gobiernos y a la sociedad civil". Por parte de la RANME participó el Académico de Numero electo Prof. Jorge Alvar con la ponencia "Seguimiento de la pandemia por Covid-19. Análisis de la RANME”

Con respecto al Museo y Banco de imágenes quiero resaltar que, dada la imposibilidad de realizar nuevas exposiciones debido a la pandemia, se ha mantenido durante todo el curso la última exposición, Ars librorum. No obstante, ha continuado la publicación de los boletines trimestrales destacando donaciones, piezas singulares y otras noticias relevantes. Se ha

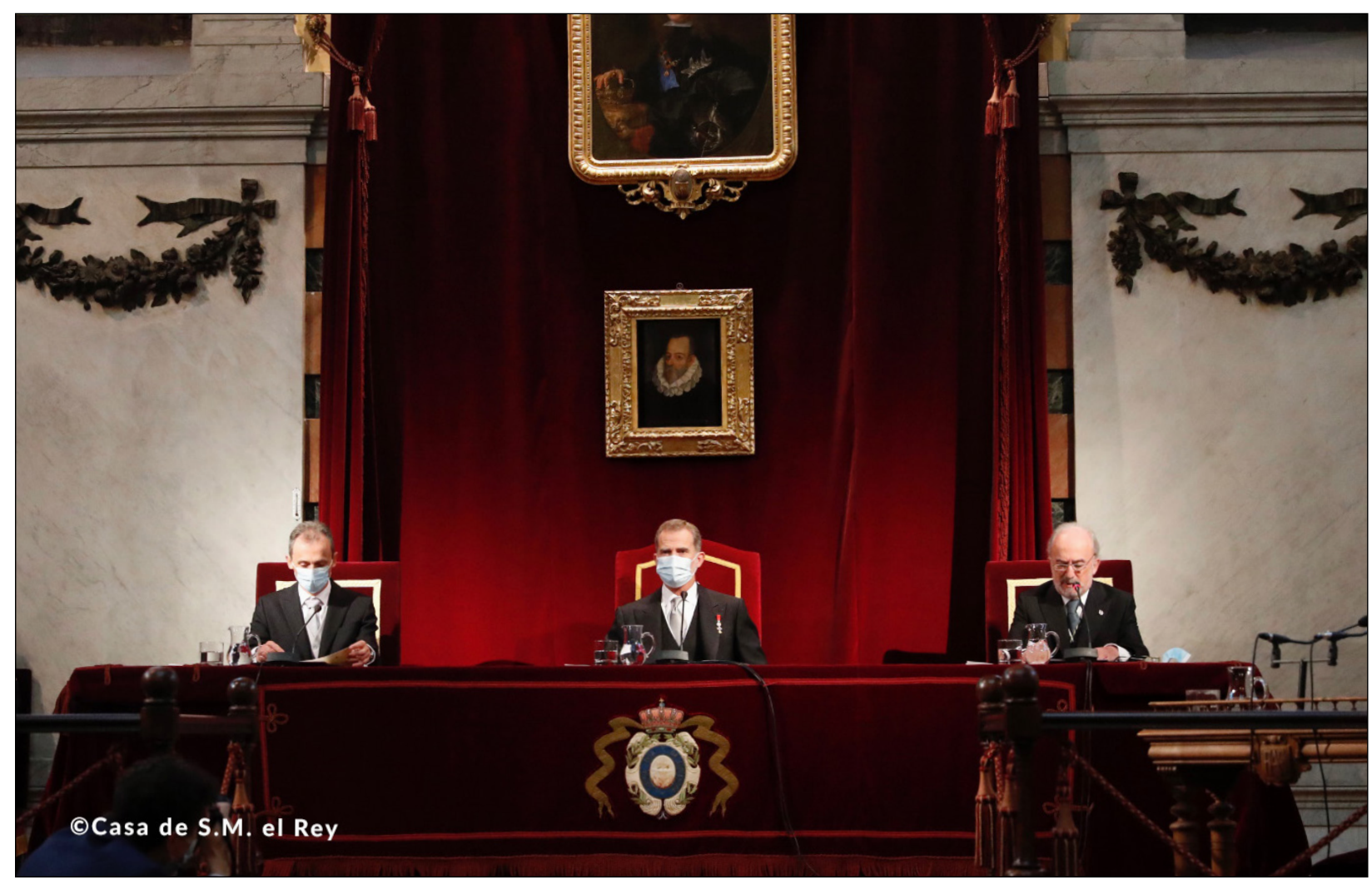

Apertura del curso de las Reales Academias 


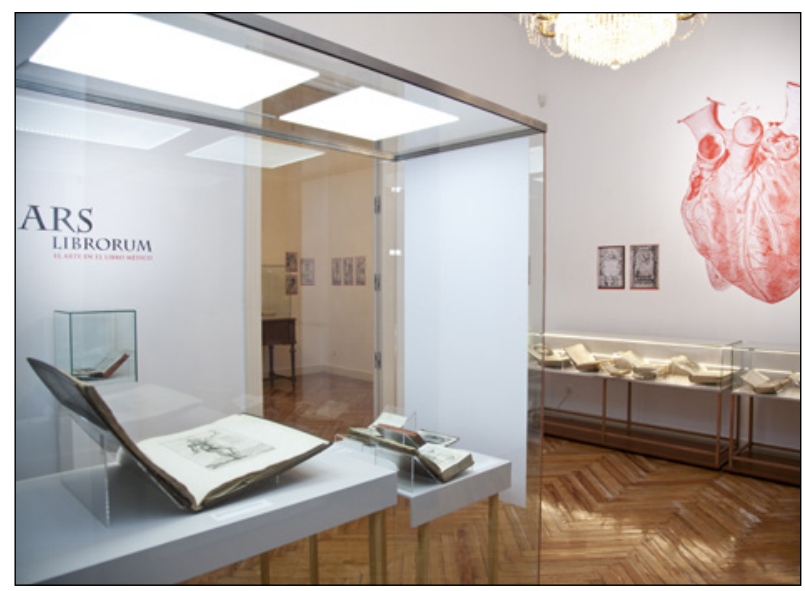

Exposición Ars Librorum

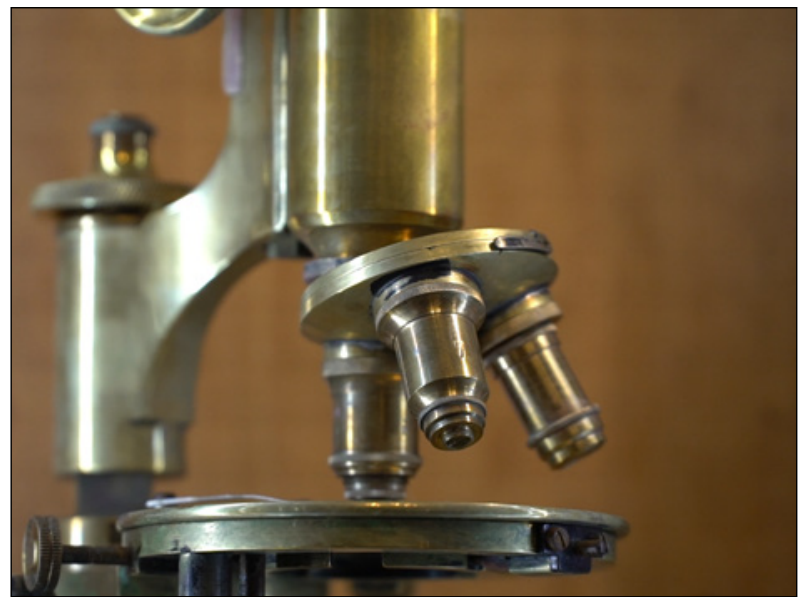

Exposición de la colección Bruni de microscopios

montado de forma estable y permanente la exposición de la colección Bruni de microscopios en la sala Botella de la biblioteca cuya solemne inauguración está pendiente de realizar debido a las limitaciones de la pandemia.

Lo que si es reseñable es la designación del Profesor Antonio Campos como nuevo director del museo y del banco de imágenes, continuando el Prof Javier Sanz Serrulla como director técnico y $D^{a}$ Celia Rodríguez como catalogadora. Aquí quiero agradecer la enorme y eficaz labor desarrollada en los últimos años por el anterior director D. Luis Pablo Rodríguez Rodríguez.

\section{Diccionario}

EL DTM está en abierto FOTO desde julio gracias al acuerdo con la Editorial Panamericana. En la actualidad se está preparando una actualización e incorporación de nuevos términos, especialmente relacionados con la Covid-19. Además, buena noticia, este año ha sido el primero en el que se ha designado una subvención al Diccionario de $50.000 €$ por parte del Ministerio de Ciencia e innovación.
La otra gran obra de la RANME es el DPTM en el que están colaborando las Academias de ALANAM, En este año se han incorporado 1241 entradas nuevas y se han procesado 862 revisiones. Es el momento de agradecer a los patrocinadores de esta obra: Fundación AMA, Fundación Iberdrola, Fundación Mapfre, Fundación Ramón Areces y Fundación ACS.

La Unidad de Terminología de la RANME, compuesta por las lexicografas Cristina González, Carmen Remacha, Laura Gómez y Ana Valverde junto con la asesora médica Elena de Terán, el etimólogo Francisco Cortés y la traductora $\mathrm{M}^{\mathrm{a}}$ Luisa Clark, no solo han trabajado en los dos diccionarios, sino que han incrementado nuestra colaboración con la Fundación del Español Urgente (Fundéu) debido a la necesidad de los medios de comunicación de obtener información fiable sobre las expresiones relacionadas con la COVID-19 y han participado en la Segunda Cumbre sobre el Español Médico en Estados Unidos.

Aquí quiero agradecer a todos los Académicos de Número y Correspondientes, así como a otros especialistas que colaboran activamente en la obra y sin los cuales no sería posible este proyecto. Agradecimiento especial a los Dres. José María Ladero y Luis García-Sancho Téllez por su especial implicación como validadores médicos.

\section{Anales de la RANME}

Se ha publicado en el año 2020 el volumen 137 que consta de dos números, el primero de 87 páginas, contiene 11 artículos sobre diversos temas médicos, el segundo, publicado el 2 de octubre, contiene 23 artículos a lo largo de 170 páginas en los que se exponen y analizan desde diferentes disciplinas y áreas del conocimiento médico la COVID-19 y el Coronavirus que la genera.

ANALES RANM recibió 73.500 consultas durante 2020 , lo que hace un promedio de 169 visitas diarias a la Plataforma de la Publicación, siendo el origen de dichas consultas España en un 32\% y el 68\% restante básicamente con origen en el continente americano. Desde septiembre de 2018, mes en el que el nuevo ANALES comenzó su andadura ha recibido 118.465 consultas por un total de 85.469 usuarios.

Siguiendo con datos estadísticos, la Web de la RANME casi duplicó el número de consultas realizadas por los usuarios, 225.285 fueron las que realizaron más de 195.000 usuarios, lo que equivale a un promedio de 533 visitas diarias, de las cuales el $33 \%$ provienen de España y el $67 \%$ restante del exterior, sobre todo Sudamérica (55\%) y Estados Unidos (10\%).

Respecto al Banco de Imágenes de la Medicina Española su progresión sigue siendo muy buena: 4.130.151 visitas con un total de 2.553.707 descargas es la balance del año 2020, arrojando unas cifras espectaculares acumuladas desde su puesta en servicio: 12.226.116 visitas y cerca de 5 millones y medio de descargar. 
La Web del Museo de Medicina Infanta Margarita tuvo 3.225 consultas realizadas por 2.814 usuarios que visitaron un total de 7.100 páginas. El 50\% son de España, el 13\% de Estados Unidos y el resto de diferentes puntos del planeta, desde Brasil a Emiratos Árabes pasando por México o Francia.

El Canal de Televisión en Internet de la Real Academia Nacional de Medicina de España, RANM.TV, tuvo un total de 27.253 espectadores que visualizaron un total de 43.067 contenidos. El 72\% de los seguidores de las retransmisiones de la RANME son españoles y el $28 \%$ restante de Latinoamérica. Mencionar que el 3,60\% proceden de EE.UU. A estas cifras hay que añadir todas las visualizaciones que se realizan a través de la difusión en vídeo en Redes Sociales lo que manifiesta un importante impacto, también audiovisual, de la actividad académica de la Real Corporación.

En cuanto a las Redes Sociales ha habido un claro incremento. En Twitter cerca del 20\%, lo que eleva el número de seguidores a 5.245, alcanzando en 2020 las 569.900 impresiones (número de veces que se ha visto un Tweet). Facebook con un incremento del 12\% hace que fuesen a 31 de diciembre 4.358 el número de seguidores teniendo un alcance de publicaciones de 87.270 usuarios.

No quiero terminar sin agradecer la labor constante con una dedicación por encima de los horarios y cometidos del personal de la Academia: Francisco Fernández gerente, Nuria Iglesias y Almudena Ramirez secretarias respectivamente de la RANME y de la FRANME, Ignacio Díaz delgado y Guiomar Arias bibliotecarios y los conserjes Mario Mínguez y Raul Sandoval.

De todo lo expuesto doy fe.

\section{DECLARACIÓN DE TRANSPARENCIA}

El autor/a de este artículo declara no tener ningún tipo de conflicto de intereses respecto a lo expuesto en el presente trabajo. 